\title{
The Limits of Critical Thinking
}

\author{
DON S. LEVI University of Oregon
}

Key Words: Deep disagreement; critical thinking; argumentative exchange; point of view; framework propositions; inarguability; conceptual framework; rule-governed activity; what is at issue; issue raised by argument; participant.

\begin{abstract}
This paper examines Robert Fogelin's suggestion that there may be deep disagreements, where no argument can address what is at issue. A number of possible bases for Fogelin's position are considered and rejected: people sometimes do not have enough in common for reasons to count as reasons; doubt is possible only against the background of framework propositions; key premises may be inarguable; argument must occur within a conceptual framework. The paper concludes by reflecting on why it is important to have a point of view when thinking critically about an argument and whether that fact constitutes a limitation as to what can be achieved by critical thinking.
\end{abstract}

I believe in the value of critical thinking in dealing with even the most controversial issues. This paper discusses a recent challenge to my faith by Robert Fogelin.' I am intrigued by his challenge because it is based on a conception of argumentation with which I am sympathetic. But I am troubled by his conclusion that a conflict, such as the one over abortion or affirmative action, may not be rationally resolvable. Although he does not make an explicit reference to critical thinking, it is clear that he is arguing for the existence of conflicts where it cannot be determined which position is best by evaluating the arguments for each position.

Fogelin's challenge to critical thinking is based on the insight that argument is possible only where certain beliefs and preferences are shared. When people disagree about so many things as to find it impossible to appeal to anything the other side will accept, then any argumentative exchange between them will be abnormal, and their conflict will be a deep disagreement. Then critical thinking cannot determine which position is best because what one side gives as arguments for its position will not even count as arguments from the other's point of view.

I am skeptical about whether deep disagreements actually exist, and I question how Fogelin can know that they do. Because I am skeptical about their existence, I wonder whether I understand what they are supposed to be or how their existence is a consequence of the way that argumentation should be conceived. I consider a number of possible bases for the claim that deep disagreements are possible: people sometimes do not have enough preferences and beliefs in common for reasons to count as reasons; doubt is possible only against the background of Wittgensteinian framework propositions; the key premises of the abortion conflict are inarguable; argument always is given within a conceptual framework. My results are negative: none of these are satisfactory bases for Fogelin's conclusion. However, what interests me more is the conception of argumentation upon which Fogelin's argument is based. Andrew Lugg claims that Fogelin has gone wrong because he thinks of the derivation of conclusions as a rule-governed activity. Although I think that this is a faulty diagnosis, considering why Lugg makes it helps to identify what is at issue: whether it is important to have a point of view when thinking critically about an argument and whether having one 
constitutes a limitation as to what can be achieved by critical thinking.

\section{From argumentation to the limits of critical thinking}

The problem that interests Fogelin about the limits of critical thinking is not a problem for formal logic. From its point of view, all that matters is whether the conclusion follows from the premises and whether the acceptance of the premises is warranted, not who is giving the argument or who is being addressed by it. Fogelin objects to formal logic's conception of argumentation because its insensitivity to rhetorical context makes those who apply it unreasonably skeptical about the correctness of argumentation. But, says Fogelin, when it is replaced with a conception that is sensitive to context, as it is in informal logic or critical thinking, then it is possible that an argument that may be correct for one audience might not even be an argument for another audience.

Fogelin is not saying that the appraisal of an argument always is a function of how its audience receives it. He concedes that an audience may be unmoved because of its own failings, because it is pig-headed or biased or otherwise unreasonable. He does not take such unreasonableness as evidence of a significant difference in beliefs and preferences with the arguer. On the contrary. He argues that the charge of pigheadedness (bias, etc.) makes sense only where there are broadly shared beliefs and preferences, where the reasons being given should be decisive for the audience if it weren't for its pig-headedness. But he insists that sometimes an argument's failure to move the audience may be due to the fact that the conditions for its even being an argument for that audience are not satisfied.

Fogelin's argument is based on his conception of argumentation:

An argument is produced by the activity of arguing and arguing is something that people do. Furthermore, they do it for a variety of reasons, and in an effort to achieve very different purposes (p. 2).

Fogelin is denying that an argument is as the logician understands it, a series of propositions (statements), one of which is designated as its conclusion, the others as its premises. The logician may concede that an actual argument is more than merely a series of propositions, but the argument that is the subject of logical analysis is reconstituted as such a series because the only thing the arguer is doing that interests the logician is offering premises in support of a conclusion. In its reconstituted form the argument has no rhetorical context; the logician understands and appraises it without thinking of it as addressing any particular audience.

Fogelin attacks the logician's conception of an argument as a sequence of propositions because he wants to complain about the consequences of the conception. One complaint is that few actual arguments turn out to be correct when restated by supplying the missing (often exceptionless) premises that enable the truth of the premises to rule out any possibility of the conclusion's being false. Another is that "deductive chauvinism" is behind the bias that there must be something wrong with any argument that employs apparently fuzzy concepts.

But Fogelin is doing more than expressing his frustration with formal logic, as can be seen by thinking about what he is doing with the different audiences be might be addressing. With someone like me he is preaching to the converted, touching a sympathetic nerve. He also is trying to avoid alienating those who believe in logic and would not concede that its rephrasings necessitate any distortion or misrepresentation. To avoid alienating them he pulls his punches by insisting that formal methods are of value in explaining and clarifying the concepts of validity, logical form, and contradiction, which he seems to think are of value outside a logic 
classroom. His real objective is not to press any objections against logic, but to explain how a problem arises when the approach to argumentation that he favors is adopted.

Fogelin is saying that the appraisal of an argument is context-sensitive, and we can illustrate what he has in mind by considering what he himself is doing. Those who believe in formal logic may want to criticize him for not giving an argument for his complaints, whereas those of us who sympathize with his frustrations will not do so. But the question of whether or not he is giving an argument is not really dependent on which audience his argument is understood to address, if you bear in mind that his objective is to complain about Logic in order to prepare the way for his claim that argument analysis should be context-sensitive.

Consider what he is doing in making this claim. Some will be skeptical about it. They will be disappointed by the little he says in explaining or defending it, confined as it is to some remarks about how the vagueness of a term in an argument may be a function of whether the context requires that the term be clearer. Unlike them, I am not skeptical, but I realize that Fogelin has other interests in this paper and is not concerned with making a case for the importance of context-sensitivity. Rather, he is reminding people like me of what we believe about argumentation in order to make us aware of the limitations of critical thinking. At the same time, he may intrigue others with the possibility that a context-sensitive conception of argumentation (with which they are not comfortable) may have relativistic consequences. For all of us, whatever our position on the need for context-sensitivity, what is important is that he is citing the fact that people who disagree on certain controversial issues also disagree on a great many other things as a basis for his position that deep disagreements exist.

How is his position to be understood? We have talked about what he is doing in complaining about formal logic and in maintaining that an argument's analysis must be context sensitive. What we need to do now is to explain what he is doing in saying that

there are disagreements, sometimes on important issues, which by their nature, are not subject to rational resolution (p. 7).

By itself this seems uncontroversial: when the alienation from the other side is extreme, there is little that the best arguments can do. When we argue we may be unwilling or unable to see things from the point of view of the opposition; we may even fail to listen or hear what they are saying. Resolution in such a dispute may be possible, but not merely by the parties marshalling evidence for a position being taken--the irrational factors also must be addressed.

But, he is not saying that some disagreements have an irrational basis. As we indicated earlier, Fogelin insists that when an arguer is pig-headed or biased or otherwise unreasonable, it is not a deep disagreement. He claims that the accusation of irrationality makes sense only against a background of shared beliefs and preferences; people are irrational when they do not see what is there for them to see. Moreover, even if those who disagree do not have a common stock of beliefs and preferences, it does not follow that their conflict has an irrational basis. His position is not supported by the fact that arguments have irrational components, and he explicitly excludes these components when defining a deep disagreement.

He is taking a very controversial position on what can be achieved by a critical thinker who is not necessarily taking sides or even prepared to address those who are doing so. He is playing Gödel by suggesting that it is not possible to determine whether and when abortion should be considered murder or whether reverse discrimination quotas are unfair. That we may not find a resolution that both sides accept-that is not controversial. Nor is it 
controversial that the two sides may disagree on a lot more than just the matter at issue, so much so that their disagreement may be said to be very deep indeed. But that no argument can be correct because none can satisfactorily address what is at issue in the argument-that is controversial, and that is what Fogelin has in mind when he says that deep disagreements exist.

But all he says about what happens when an argumentative exchange is not normal is:

The language of argument may persist, but it becomes pointless since it makes an appeal to something that does not exist: a shared background of beliefs and preferences (p. 5).

Arguments on either side of the abortion question often are question-begging. Perhaps this is all Fogelin has in mind when he talks about how the language of argument becomes pointless when the argumentative context is abnormal. After all, arguers who are begging the question are not really giving an argument, in the sense in which giving an argument presupposes that what is at issue in the argument is being addressed. They are arguing-Fogelin needs to be clear on this point. But, because they are begging the question, their arguments may be said to be pointless, to the extent that they do not address the issue. Fogelin's talk of the conditions for arguing suggests that he is thinking of someone who is uttering the words but whose actions misfire and become little more than sound and fury. But it would be wrong for him to suggest that my prochoice arguments will make no sense to someone like Jerry Falwell, who is pro-life and whose values are significantly different from mine. Falwell will understand them all right, just as he will understand that $I$ am arguing against him, but he will not understand how they are responsive to what he thinks is at issue, presumably because they are not responsive. Fogelin says nothing to indicate that when he refers to the conditions that make argument possible he means the conditions that make it possible for an argument not to beg the question. But perhaps this is how he should be understood.

Otherwise we have to understand him to be taking the untenable position that when arguers deeply disagree they cannot even adopt the opposition's premises for the sake of argument, as when the prochoicer argues that the right-to-lifer must take the position that an abortion for a pregnancy due to rape is not permissible because the fetus' right to life is not lost just because of how it was conceived. Fogelin emphasizes how extensive the differences are between the two sides, but, as Andrew Lugg suggests, the fact that arguments can be given which force the opposition to adjust or even change their positions requires that their exchange takes place in a context of shared beliefs and preferences. ${ }^{2}$ If anything, Lugg suggests, the practice of arguing seems to aim at the lessening of disagreement. We take a position and others disagree. If we engage with them in discussion and argument, we find ourselves trying to understand what they are saying, even as we consider how we might respond to them. The very attempt at helping them to see things our way leads us to restate our views in a form more acceptable to our opposition-the very process of arguing leads us closer to agreement. When argument has brought us closer together it is because we have been guided by what we discovered in the process of the dialectic rather than by what we knew before we engaged in it. Lugg contrasts this conception of the practice of arguing with one where arguers are anchored to the position from which they have started, and instead of moving towards agreement they fall back to their original positions, perhaps because they have so much invested in being right, i.e., because they are so pig-headed. 
But Fogelin cannot be understood to be taking a position on conflict resolution. ${ }^{3}$ He says nothing to imply that those engaged in a deep disagreement will be unable to find a compromise agreeable to both sides. His interest is in what can be achieved by critical thinking, not in what can be accomplished by negotiation or any other political activity. When he says that sometimes rational resolution is not possible he is making a claim about the limits of what can be achieved by critical thinking in addressing what is at issue in the argument.

\section{Normal and abnormal argumentative exchanges}

Grant, for the sake of argument, that the two sides in a dispute like the one over abortion or affirmative action may have differences which range over a significant number of other beliefs and preferences. Nevertheless, the debate does not seem to involve anything that might be referred to merely as a preference. It is not a matter of preference when a pro-lifer sees abortion as killing babies or a pro-choicer sees it as self-defense. And if there are differences in belief among the disputants, some of these beliefs seem to be expressions of bias or are otherwise mistaken. So, the fact that people have different beliefs and preferences doesn't seem to argue for any Gödelian conclusion about the possibility of resolving controversial questions,

To see how Fogelin is thinking, you need to consider his example of an argument over which route to take home after shopping for, among other things, frozen food and fresh fish. The traffic at that time of day is a factor; so too is the fact that frozen food melts and unrefrigerated fish begins to stink. The disagreement is not deep if it it takes place in a context where the arguers have a common base of shared beliefs and preferences, for example, for food that keeps, for avoiding traffic jams, for being spared the stink of unrefrigerated fish.
When would it be deep? Mere preferences seem inarguable, but they do not seem to be the basis for a deep disagreement. Is pistachio ice cream tastier than coffee almond fudge? It is a matter of preference. So, too, is a preference for apples over pears, or salmon over trout. We may argue about which to buy if we can only buy one-your preference or mine. If each dislikes what the other prefers, then the disagreement may be resolvable if there are other options, such as buying something else, or getting half of each, something that may prove a satisfactory compromise if the alternative is getting nothing at all.

Fogelin seems to be thinking of something different: a preference, if it is a preference at all, for getting caught in a traffic jam, the frozen food's melting before it can be put in the freezer, or the fish's stinking up the car. Which route should we take to get home on time? If you want the trip to take a long time or the food to spoil, then we will be arguing at cross purposes, especially if you are not forthright about it. If I know that you want to be late in order to avoid meeting someone, we can try to find ways for us both to get what we want. But if you don't trust me with the truth, we may continue to argue fruitlessly. Here the problem is not that the argument is unresolvable, but that we are addressing the wrong issue-which route to take to get home quickly, rather than whether to get home on time.

Fogelin may be thinking of something perverse-a preference for spoiled food or traffic jams, not as a means to an end, but for their own sake. You want to take that route because even though you want to get home, you want to be in a traffic jam more. Because we both want to get home, perhaps we can agree to let you indulge your taste for traffic jams some other time. But then I am unsure what that taste involves. Perhaps you like being around frustrated and angry people; perhaps you like the smell of gasoline exhaust or the feeling of 
being stopped while surrounded by so many cars. Either your preferences can be indulged some other way or they are the kind of things that Fogelin ruled out earlier when he insisted that he is not talking about an arguer who is behaving irrationally. Surely such a perverse preference is not what he has in mind when he talks about the need for a shared background of beliefs and preferences on the part of those engaged in a normal argumentative exchange.

Why are we wondering what Fogelin is referring to as "preferences?" He is right in thinking that people really do have different preferences, and that there is no point in arguing about many of them. The problem is how the kind of deep disagreements he has in mind could depend on such differences in preferences. By contrast, disagreements on many social and political questions do seem to turn on differences in beliefs. But, at least some of these beliefs, such as in the inherent inferiority of a certain race, are expressions of bias and as such are ruled out by Fogelin as a basis for a deep disagreement. Because they are biased some of the arguers may not be moved by the arguments of the other side, but it does not follow that critical thinking cannot reveal whether they should be moved by them.

\section{Framework propositions}

His argument for the existence of deep disagreement requires more than the possibility that those who disagree may not have a background of shared beliefs. It needs these beliefs to be the kinds of things that cannot be critically evaluated.

When he thinks of beliefs that cannot be evaluated he is reminded of $O n$ Certainty. Indeed, it is the opportunity to apply Wittgenstein's insights about what is wrong with philosophical skepticism that seems to motivate Fogelin. Wittgenstein claims that certain "hinge propositions" - Fogelin calls them "frame- work propositions"-must be exempt from doubt in order for doubt to even be possible. These propositions, in Wittgenstein's words, are the "rock bottom substratum of my convictions," the "scaffolding of our thoughts," or the "language game foundations." They are inarguable.

Grant, for the sake of argument, the existence of framework propositions; how can that be used to argue for the existence of deep disagreements? The propositions Wittgenstein cites, such as Moore's claim to have two hands, are absolutely uncontroversial. How puzzling, as Andrew Lugg points out, that Fogelin refers to the fact that there are framework propositions which none of us could doubt, as evidence that there might be something comparable in connection with the most controversial questions! ${ }^{4}$

Things would be less puzzling if it were obvious that framework propositions exist. How can Moore know that he has a hand when he does not see it, how can he know anything external exists when he does not really perceive it, at least not immediately or directly? And so on for other doubts. In each case the skeptic offers a characterization of our evidence that makes it seem inadequate to support the claim to know. Wittgenstein's response is that the existence of physical objects, other minds, and the like, cannot be established; rather, their existence constitutes the scaffolding for everything else we think and do.

My life shows that I know or am certain that there is a chair over there, or a door, and so on.-I tell a friend, e.g., "Take that chair over there." "Shut the door."

Here he is making the uncontroversial claim that my actions reveal what I know or believe.

More problematic is the assertion that my life shows what I believe about metaphysical questions such as whether material objects exist as the cause of my sense impressions. After all, nothing I say or do 
seems to reveal that I believe in the causal theory of perception, or some theory about the relation between sense data and material object claims. Whatever he means by saying that our lives show that we know that there is chair over there, Wittgenstein cannot mean that they show that a metaphysical belief about the existence of material objects is true.

If not metaphysical ones, then what propositions or beliefs are supposed to be bedrock? The answer that suggests itself is that there must be some things immune from ordinary as opposed to metaphysical doubt. You can question whether it really is salt in the salt shaker. Some other substances look like salt; perhaps the kids have played a prank and have switched the salt and sugar. But that you are holding a shaker, that you have a hand (that is doing the holding), and so on-such things are supposed to be bedrock.

But circumstances can be imagined where even these supposed bedrock beliefs can be doubted. For example, you may have some pop art sculptures that look exactly like household objects or your hand may have been mangled and you wake up from surgery not knowing whether it has been amputated. Admittedly, in many circumstances no one would (or could) entertain such doubts, but this is hardly the same thing as suggesting that there are propositions with a status sufficiently privileged to qualify as framework propositions.

Not only is the claim that framework propositions exist puzzling; so is the suggestion that what is true for metaphysical doubt also may be true of argument over certain controversial issues. After all, claims earn their status as framework propositions because everyone accepts them, whereas those who disagree over something like the morality of abortion are supposed to be accepting conflicting framework propositions. ${ }^{6}$ Grant, for the sake of argument, that the very possibility of argument depends on both the arguer and the audience accepting the same framework propositions; how could we know that the different sides on abortion do not do so? The answer must be based on an understanding of the nature of the abortion controversy, rather than on any transcendental argument about the conditions for argument to be possible.

\section{The inarguability of the key abortion premise}

The abortion conflict is not resolvable because each side's argument relies on a key premise that is like an axiominarguable but crucial to the argument. Many of Fogelin's readers will understand him to be taking this position. That the fetus is or is not a person he refers to as a framework proposition, as he also refers, in connection with the conflict over affirmative action, to the proposition that groups as well as individuals do or do not have a moral claim against a society that has oppressed them. His position that these are framework propositions gets support from the fact that many of the arguments on each side are question-begging, as we would expect if they are derived from mutually incompatible axiom-like premises.

That whether or when the fetus is a person is inarguable has not prevented many philosophers from arguing for a position on the question by invoking some principle about what it takes to be a person. Perhaps Fogelin thinks (as I do) that the use of such a principle is question-begging, since the validity of the principle depends, among other things, on whether it has been correctly applied to abortion. Nevertheless, if philosophical literature on abortion is any evidence at all, then any claim about when the fetus is a person is arguable.

But, the real problem with the axiomatic view is that it makes the commitment to the contradictory starting points mysterious-it leaves out the people whose arguments rely on these starting 
points. Or, rather, it makes it seem as though they just find themselves relying on these axioms, as we do when we philosophize and ask ourselves how we would think if we operated on a certain premise. I take Fogelin to be rejecting such an approach when he emphasizes how much argument requires a context of shared beliefs and preferences. He would not say this if he were thinking that the difference between the two sides of the abortion dispute is that they happen to start from different axiom-like premises. The axiom view of the dispute should be rejected because it "depsychologizes" the arguments for either side.

Perhaps Fogelin's talk of how people who deeply disagree cannot agree on procedures for settling things is a clue to his thinking. He attributes to some right-tolifers the position that

at conception, or to be delicate, very shortly after conception, an immortal soul enters into the fertilized egg, and with this, personhood is attained. Why should one believe this? Well, this is part of a wider tradition, grounded in revelation, and sustained and deepened by faith (p. 5).

$\mathrm{He}$ is making the dependence on different key premises less mysterious by explaining that the pro-lifer knows when the fetus is a person because he is acting in obedience to a religious authority. Fogelin does not suggest that the other side also is relying on a procedure; presumably the two sides disagree because one invokes a procedure which the other does not accept as valid. And their disagreement is deep because it depends on a commitment that gives meaning to the lives of believers, a commitment not shared by the other side.

By emphasizing how much their argument depends on revelation he seems to be refusing to take it seriously as a moral argument. Perhaps the procedure he has in mind involves some method for determining the will of God on the morality of abortion, such as divinely inspired inter- pretation of the Bible. But how is the use of such a procedure to be understood as an argument? The problem, to borrow from the Euthyphro, is whether God (or a religious leader) says that the fetus is a person because it is a person. Admittedly, many pro-lifers are certain that abortion is murder because that is what their religion tells them. But believing or knowing something needs to be distinguished from the argument for the belief, especially when that argument is to address even non-believers. Revelation may be the explanation for why people take the pro-life side, but it is not part of the argument for that side.

Fogelin's view that the abortion conflict is a deep disagreement may have its source in his failure to appreciate how anyone who opposes abortion really could have an argument. If so, that would explain why he would characterize the conflict as he does. This alienation from the other side is not to be confused with what we are calling a deep disagreement. But the alienation does explain why conflict is often so difficult to resolve. If you do not see yourself in the opposition, if you cannot imagine thinking and saying what they do, then your differences with them are very deep. But they are not deep enough to constitute a deep disagreement, because that requires that the issues raised by the conflict not be resolvable even by someone who can see things from the different points of view.

Roger Wertheimer, who does think of the key premise for each side as axiomlike, explains how each side becomes committed to it as the effect of a natural response to the fetus:

If you are led in one direction rather than the other, that is not because of logic, but because you respond in a certain way to certain facts. $^{8}$

He is trying to explain the adoption of the conflicting starting points as a function of how people respond differently to a fetus. In doing so he helps us to see what Fogelin has in mind when he emphasizes how the 
parties to the abortion dispute are so different in their beliefs and preferences. Interestingly, Wertheimer also invokes Wittgenstein in stating his position: the different responses to the fetus are "disagreement in judgements," in "forms of life."

He is thinking of the responses, not of women contemplating an abortion, but of people reacting when shown pictures of a fetus. Would he want to maintain that those who oppose abortion respond more positively to those pictures? And even if it were true that they did-and I know no evidence to support it-what would that show about the strength of feeling for the baby itself? Some pro-lifers may like to shock us with pictures of fetuses, but there is no reason to think that we take different sides because we respond differently to these images. The only responses Wertheimer does cite are not to the fetus but to arguments for and against abortion's being murder. To suggest that differences in confronting the challenge of saying just when the fetus becomes a person are due to differences in natural responses would seem little more than a confession that these differences are quite inexplicable.

His explanation is interesting because it tries to explain where the key conflicting premises come from, though many philosophers think a consideration of how the arguers come to adopt a premise is irrelevant to a consideration of the argument itself. As they see it, you can consider an argument for or against abortion without knowing anything about who is giving the argument - her point of view; what divides her from her opposition; her interests and concerns; whom she might be addressing with her argument. In other words, you can give yourself an argument to consider without knowing anything about its rhetorical context.

I take it that Fogelin, like Wertheimer, thinks it is relevant how the arguers come to start from different premises, and that it informs what he wants to say about deep disagreements: when we inquire into the source of a deep disagreement, we do not simply find isolated propositions ("The fetus is a person."), but instead a whole system of mutually supporting propositions (and paradigms, models, styles of acting and thinking) that constitute, if I may use the phrase, a form of life (pp. 5-6).

A disagreement over something like abortion is misleadingly characterized as a disagreement over a key premise. That characterization ignores the fact that the people who are arguing have certain beliefs and preferences in terms of which what they say must be understood. This is what Fogelin has in mind when he says it is not true that the abortion conflict "takes place within a context of broadly shared beliefs and preferences."

To identify the relevant beliefs and preferences, you need to supply a rhetorical context. For example, think of the right-to-lifer as talking directly to a woman contemplating having an abortion. "You may find it inconvenient to go to term, but if you didn't want to have a baby you shouldn't have had sex." To the woman who has been raped: "You are displacing your anger at your assailant onto the baby. Heal yourself by getting in touch with your maternal feelings." ${ }^{0}$ To the young girl: "Don't let your guilt and shame interfere with your doing the right thing. If your parents won't help care for the baby, put it up for adoption." He tries to shock her into a realization of what she is contemplating by showing her pictures of a fetus, but he does not really think of her as a murderer but as someone who is alienated from her real nature. "Don't let those greedy abortionists get you to do what you do not want to do. They are taking advantage of you when you are most vulnerable, when you are frightened about being pregnant and worried about how you could care for a baby."

These reactions by some opponents of abortion provide us with access to their beliefs: sex should be confined to marriage; a woman should not have sex unless she is 
ready to be a mother (or to give the baby up for adoption); any pregnant woman really wants to be a mother; to be fulfilled as a person she needs to have a baby. Reactions to questions about birth control and about the handicaps of babies born to women who won't be able to get abortions reveal the existence of other beliefs and preferences, such as for pregnancy as a deterrent for sex outside marriage and against child care, head start programs, or other measures designed to compensate for a child's unfortunate circumstances. ${ }^{11}$

Of course, not everyone who opposes abortion has these beliefs and preferences. But they are held by a great many prolifers, and their conflict with the other side is a deep one in the sense of being a conflict in forms of life. I have concentrated on the beliefs and preferences of pro-lifers because they are easier to identify, especially by someone like myself who is opposed to their position; but pro-choicers also have their beliefs and preferences, one of which seems to be for a sex life with few if any restrictions.

The problem is that these beliefs and preferences can be subjected to criticism, and on the kinds of grounds that Fogelin specifically excludes as a basis for a deep disagreement. A woman can find fulfillment only as a wife and mother? This is a sexist attitude, the kind of unreasonable or irrational attitude that we are not to be considering when talking about deep disagreements. Fogelin is not suggesting that there is a deep disagreement over abortion because one side is sexist. Pregnancy should be a deterrent for having sex? Sex is only for those who are married? These and other expressions of the beliefs and preferences of right-to-lifers also can be criticized as unreasonable or perhaps even irrational.

It is time for a progress report. Fogelin's thinking is based on the insight that much of the arguing on a controversial issue like abortion is question-begging. The problem is how it follows that the controversy is a deep disagreement. He makes the connection by relying on two philosophical theses: one is that there must be conditions that have to be satisfied in order for a speech act like arguing to be possible; the other is that framework propositions must be accepted in order for something like doubt to be expressed. Not only are these theses dubious, but, as we have seen, it is questionable how they establish that there are deep disagreements. Fogelin himself is committed to the view that critical thinking is concerned with arguments that are products of a human activity. For him, those on opposite sides of the abortion conflict do not happen to adopt conflicting premises; rather their disagreement is a reflection of other differences that are so deep that the opponents must be considered as participating in different forms of life. If so, then the premises he identifies as key do not seem to be anything like what he has in mind for framework propositions.

Given that the parties to the abortion controversy adopt contradictory premises about the status of the fetus, what follows about the possibility of coming to an understanding of the morality of abortion? Fogelin is right in thinking that much of the arguing is question-begging because each side operates from mutually incompatible premises; but this does not support the stronger conclusion that the only arguing possible must be question-begging, any more than it supports the conclusion that critical thinking is unable to determine which side is right. We cited Lugg earlier as making the valid point that arguing can be done on the grounds of the opposition. But the real challenge to Fogelin's conception of the controversy is whether the issue is defined properly as the problem of whether abortion is murder. In the next section of this paper, we consider an essay which insists not only that that is the wrong way to define the issue, but that defining it Fogelin's way is a function of his conceptual framework. 


\section{Karen Warren on conceptual frameworks}

One contributor to Informal Logic, Karen Warren, may offer a way of improving on Fogelin's argument. As we have seen, the problem with Fogelin's argument is that there seems no reason for thinking that a conflict over abortion or affirmative action is a conflict in framework propositions. Instead of referring to the propositions that must be believed by the parties to a controversy in order for argument between them to be possible, Warren refers to what people believe because of their class, ethnic identification, gender, affectional preference, etc.

She claims that all of us, whether arguing or reflecting on an argument, are operating with

\begin{abstract}
a set of basic beliefs, values, attitudes, and assumptions which explain, shape and reflect our view of ourselves and our world. Conceptual frameworks are influenced by such factors as sex-gender, class, race/ ethnicity, age, affectional preference, and nationality. Although one's conceptual framework can change, all individuals perceive and construct what they perceive, know and value through some conceptual framework. At any given time, a conceptual framework functions for an individual as a finite lens, a "field of vision", in and through which information and experiences are filtered. As such, conceptual frameworks set boundaries on what one "sees".
\end{abstract}

She is saying that how we argue or think about arguments is going to be determined by our "conceptual framework." Her concern is for how our social and cultural history sets boundaries on what we can see morally and politically, not in how language defines metaphysical categories such as thing, event or action, in terms of which we are supposed to see the world. ${ }^{13}$ For Wittgenstein and Fogelin, certain beliefs have to be bedrock because the very possibility of our talking as we do depends on our adopting them; whereas for Warren we value things as we do because of our class, gender, race, sexual preference, etc.
As Fogelin insists, arguing is something we do. But so is critical thinking. And for Warren it is something we cannot help doing from a particular "conceptual framework."

She explains what she has in mind by citing feminist critiques of certain research into gender-based differences. ${ }^{14}$ Researchers who confined their studies to fighting behavior ignored cases of female dominance or control in choice of mates even though they claimed that their results applied to all aggressive behavior. They ignored them because they were operating from a (patriarchal) conceptual framework, a male perspective that thinks of aggression and dominance exclusively in terms of its own experience and concerns.

But even these researchers are not so limited by that perspective that they cannot see how they were mistaken. Or, to put the point in the first person: granted, that as a white male my experiences, interests and concerns limit how I see things. But I would like to think that I can see things from other points of view. Not only can I speak for myself, I can also speak for people whose views are ignored because they lack the power to be heard.

The presumption that I can speak for others, especially those who are more marginal than $I$, is itself an expression of a dominant patriarchal perspective. This would be Warren's response. We philosophers may think we understand what is involved in abortion, but we seem to ignore the experience of those most directly affected by our discourse. To take their experience into account and give it the weight it deserves we must be able to hear what women who seek abortions are saying rather than to presume that we know what they would say.

But in saying that critical thinking demands that we learn how things are from other points of view I am not presuming to know what others think or feel. I know that some research may be required, and I know, too, how important it is to create a situation where the powerless feel 
confident enough to talk about their experiences. But no conceptual framework seems to act as a constraint on me. Warren may think that we are so different that I cannot learn from listening to women talk about their experiences. But I believe that we are sufficiently alike that I can see things from their point of view as well as from my own.

Warren claims that a conceptual framework determines not only how we think when addressing an issue, but also how the issue itself is defined. When, as philosophers, we see the problem of abortion "in terms of alleged rights of relevant parties and/or in terms of governing rules or principles," 15 we do so from a point of view that Warren wants to criticize as an oppressive conceptual framework. We consider it more important to determine the scope and jurisdiction of certain principles and to apply them consistently than to understand how the abortion is a problem for the pregnant woman. In doing so we seem to be expressing distrust or condescension by telling the woman that her experiences and feelings do not matter. You have to wonder about the will to power of those of us who presume to know how a woman should feel about the baby or herself when contemplating an abortion, especially when we insist that ours is the only valid point of view for discovering the truth about the issue.

But we can reject the approach taken to the problem of abortion by (most) philosophers. By considering how things look from the woman's point of view, we may discover that the problem should be defined differently. Curiously, rather than emphasize the importance of considering the points of view of women with unwanted pregnancies, Warren defines the problem for them, in terms of who is to exercise control over the decision to have a baby. Women with unwanted pregnancies have other concerns, including feeling that they are doing something wrong in having an abortion. Warren seems to want to argue that merely by expressing these other concerns women are undermining their autonomy. In doing so, she seems to be saying that she knows better than the women involved what problem they are confronting.

Warren would not be disturbed by the suggestion that even an open-minded person must give arguments on the morality of abortion that will be question-begging. As she sees it, open-mindedness, like any other virtue in critical thinking, must be exercised within a conceptual framework. Since she is operating from a feminist conceptual framework, it is only from within that perspective that she can be open-minded.

From a feminist point of view, some conceptual frameworks are better than others, and not all positions are worthy of equal consideration. . . From a feminist point of view, contemporary Western society is thoroughly structured by race, class and sex/gender factors; as such, in contemporary Western society at least, there is no currently available value-neutral conceptual framework within which the trait of openmindedness can be exercised ( p. 38).

Warren insists that the failure to engage the argument for the impermissibility of abortion is not really evidence of closedmindedness because the claim that the fetus is a person (from conception) is made from within a patriarchal conceptual framework. However question begging the feminist approach may seem from the point of view of the opposition, critical thinking, as Warren wants to see it done, does not require the kind of openmindedness that takes seriously positions and arguments that are given from within an oppressive conceptual framework.

The bone of contention between Warren and myself is whether all discourse, including my analysis of her argument, is to be analyzed as an expression of power. I like to think that I am not so dominated by my interests, whether as an individual, or as a gender or class member, that I cannot "see" past those interests to consider those of people less fortunate than 
myself. Warren may reply by saying that this is what she would expect someone to say who is determined to maintain his power even over the debate over whether all discourse is an assertion of power. But all she seems to have going for her is the metaphor of a conceptual framework as a lens or field of vision. She needs more. She needs to give some reason for thinking that we cannot see things from the point of view of those less fortunate than ourselves.

\section{Andrew Lugg's diagnosis of Fogelin's mistake}

Do deep disagreements exist? Fogelin's argument takes as its point of departure an insight: when arguers disagree on all sorts of fundamental matters, they will find it difficult to avoid begging the question. But to argue for his conclusion, that there are controversies where any attempt at determining who is right will be questionbegging, he needs more. As we have seen, he fails to receive the help he needs from the presumption that there must be conditions for speech acts to be possible or that there must exist framework propositions which have to be believed in order for certain discourse to be possible. But even if his argument fails, the question whether deep disagreements exist remains to be addressed.

The problem is that nothing seems to turn on their existence. He does not suggest that we argue or behave differently. Rather, it is the opportunity to apply the transcendental argument about what has to be true in order for argument to be possible that seems to interest Fogelin, not the existence of deep disagreements themselves. Even if I am right about the fact that he is arguing for the existence of limits as to what can be achieved by critical thinking, it is not clear what turns on the existence of these limits.

In his critique of Fogelin's argument, Andrew Lugg complains that he has a faulty conception of arguing as a rule- governed derivation of conclusions rather than as something that can be done well or badly like riding a bicycle or painting a picture. Lugg does not explain or illustrate the contrast (is rule-governed behavior not creative?); but the real problem with his diagnosis is that it does not fit Fogelin. Lugg thinks otherwise because he is trying to explain why Fogelin fails to take into account how arguers are affected by the process of arguing. His explanation is that Fogelin thinks that each side argues as it does in the abortion controversy because it starts from a key premise and the rules of logic dictate exactly what must be concluded given that starting point.

But, there is no real evidence that Fogelin thinks of arguing as a rulegoverned derivation of conclusions. Fogelin's insight is that so many of the arguments on the permissibility of abortion are question begging, but this does not imply anything about how people have to argue or how an argument should be conceived. That arguing is open-ended and can lead to compromise and agreement even between people who disagree in their forms of life, that even when the issue cannot be directly addressed there are other effective modes of argumentation-all these valid points made by Lugg would be conceded by Fogelin; but he would deny that deriving conclusions is a rule-governed activity.

Perhaps the fact that there are no practical implications of Fogelin's view confuses Lugg, who seems to be adopting the perspective of a participant in the argument. Participants bring certain interests and concerns to the argument which explain why they are arguing. One of these concerns may be the desire to find an accommodation with the other side, especially if an agreement on a policy must be reached. Fogelin's perspective seems to be that of a non-participant. He is intrigued by the implications for a theory of argument of Wittgenstein's discoveries about the existence of framework propositions. An argument is produced by the activity of 
arguing; what does that imply about the possibility that some disagreements are not resolvable? Nothing turns on the question; it is of interest in its own right.

\section{Conclusion: the issue raised by Fogelin's argument}

What would it be to resolve the problem of abortion? This question arises when we think about why we are engaging in critical thinking, and, in particular, when we think about what kind of question we are trying to answer about abortion. From the third party perspective there is only the intellectual exercise of resolving the question of how or whether abortion can be distinguished from infanticide. But from the standpoint of a woman with an unwanted pregnancy or someone counseling her, there are problems that have to do with such things as the degree of support of her loved ones, the extent of her other commitments, the dangers to her health, her ability to take on responsibility for taking care of a baby, and even her desire to have a baby. Fogelin is interested only in the prolife/pro-choice dispute when he raises the question of resolvability. He is not interested in whether the problems confronted by the woman herself or someone counseling her are resolvable. The issue raised for us by his discussion is whether the problem, as defined from the perspective of the non-participant, is a legitimate problem.

The real issue about what can be achieved by critical thinking is, how can valid results be obtained from the perspective of a non-participant? After all, we can- not know what to say about an argument if we do not know what is at issue. When critical thinking is not informed by concerns, it is not possible to say why it matters how the argument is resolved. To say why it matters you must have a point of view in terms of which things matter.

But the unavoidability of a point of view does not constitute a limitation on what can be achieved by critical thinking. I wrote this paper in order to make this point, as well as to reinforce it by making another one about what we should be doing when we think critically. We should be seeking a better understanding of the issues, not a final verdict on the argument. We offer a formulation of what is at issue to guide us in paraphrasing the argument; we raise questions about the argument and anticipate responses to them; we reformulate what is at issue and restate the argument to reflect what we have discovered in the course of this dialectic. Questions arise that could not have been raised in the absence of the dialectic; new or altered points of view are generated in the process of critical thinking. If our object is to reach a verdict about the argument, then the open-endedness of the dialectic will be disturbing. But we should be thinking critically in order to acquire a better understanding of things; and an understanding is dynamic - it may never stop growing. When the focus is not on the argument itself but on the issues that arise in the course of the dialectic, then critical thinking will not be seen as limited just because it must be conducted from a certain point of view.

\section{Notes}

Robert Fogelin, "The Logic of Deep Disagreements," Informal Logic, VII, 1 (Winter, 1985).

This point is made in Andrew Lugg, "Deep Disagreement and Informal Logic: No Cause for Alarm," Informal Logic, VIII, I (Winter 1986), p. 48.
3 The need to clarify what is meant by "resolution" was pointed out to me by Richard Feldman who, like Andrew Lugg, was a referee for an earlier version of this paper.

4 Lugg, op. cit., p. 50. 
Ludwig Wittgenstein, On Certainty, translated by D. Paul and G.E.M. Anscombe (Oxford: Blackwell, 1969), section 7 .

6 Richard Feldman suggests that the doctrine that the ensoulment that makes someone a person takes place at conception (or quickening?) is just such a metaphysical framework proposition. I'm not sure why he thinks it metaphysical at all. But the real problem is with how it could be a framework proposition. Not only have co-religionists disagreed about when ensoulment takes place (or even whether it takes place), but by no stretch of the imagination could the conviction that a fetus acquires a soul at conception be considered the kind of proposition that must be exempt from doubt in order for doubt to be possible. Of course, Fogelin could have something else in mind, and the next section of this paper considers such a possibility.

7 The term is borrowed from Andrew Lugg, op. cit., p. 50, where he suggests that when the deriving of conclusions is treated as rulegoverned the activity is "depsychologized". Ironically, he claims that Fogelin himself is guilty of this depsychologizing in his argument for the existence of deep disagreements. The irony is that Fogelin is at great pains to insist that argumentation should not be depsychologized, and we are taking him at his word in interpreting him to be saying that the key premise in the abortion argument must be understood as part of a system of beliefs and preferences. Lugg's diagnosis is discussed in the last section of this paper.

8 Roger Wertheimer, "Understanding the Abortion Argument," in Joel Feinberg, editot, Abortion (Belmont, Calif.: Wadsworth, 1973), p. 37.
9 See, for example, Judith Thomson, "A Defense of Abortion," Philosophy and Public Affairs, I, I (1971), 47-66, an essay which has dominated the philosophical discussion of abortion. Thomson begins her essay with the premise that the fetus is a person from conception. The question that interests her is how the conclusion that an abortion is impermissible follows from this premise. But she has no interest in who is giving the argument, why it is being given or whom it is addressing.

10 See Sandra Mahkorn and William Dolan, "Sexual Assault Pregnancy," in Thomas Hilgers et al. (eds.), New Perspectives on Human Abortion (Frederick, Md: University Press of America, 1981), pp. 182-98, for an expression of this attitude.

11 See Kirstin Luker, Abortion and the Politics of Motherhood (Berkeley, University of California Press, 1984) for a detailed examination of the beliefs and values of right-to-lifers.

12 Karen Warren. "Critical Thinking and Feminism," Informal Logic, X, 1 (Winter 1988), p. 32.

13 See Donald Davidson, "On the Very Idea of a Conceptual Scheme," in Inquiries into Truth and Interpretation (Oxford: Clarendon Press, 1984).

14 Donna Hardy, "Primatology is Politics by Other Means," and Sarah Blaffer Hardy, "Empathy, Polyandry, and the Myth of the Coy Female," in Ruth Bleier, editor, Feminist Approaches to Science (New York: Pergamon Press, 1984), 77-118, and 119-146, respectively.

15 Warren, op. cit., p. 35.

\author{
DON S. LEVI \\ DEPARTMENT OF PHILOSOPHY \\ UNIVERSITY OF OREGON \\ EUCENE, OR 97403-1295
}

